\title{
¿Estado Post-Neoliberal y Desarrollo en América Latina? Un Análisis del Caso Argentino
}

http://dx.doi.org/10.21527/2237-6453.2019.48.9-33

Recebido em: 10/3/2018

Aceito em: 19/3/2019

\section{Victor Ramiro Fernández, ${ }^{1}$ Carolina Teresita Lauxmann²}

\begin{abstract}
RESUMEN
Sobre finales del siglo pasado, los Estados de los países Latinoamericanos han experimentados transformaciones en su forma organizativa y su lógica implicativa para con el sector productivo industrial, que han dado lugar a cambios en las estrategias de acumulación del capital en la región, agudizando su posicionamiento periférico. Ante este escenario, a inicios del siglo 21, comenzaron a emerger una serie de reacciones neodesarrollistas que procuraban conformar estrategias acumulativas más virtuosas, sustentadoras de un desarrollo más inclusivo e igualador. ¿Han podido estas reacciones avanzar en la conformación de un Estado alternativo -superador- al neoliberal que permita viabilizar dichas estrategias acumulativas? El trabajo procura dar respuesta a esta pregunta analizando la evolución de las formas organizativas y lógicas implicativas del Estado argentino, caso paradigmático en la región tanto de la experimentación neoliberal como de las reacciones neodesarrollistas. Los estudios arrojan la presencia de cambios cosméticos en la configuración estatal y su lógica de implicación en la faz productiva industrial, los que no permitieron cualificar las dinámicas de acumulación domésticas.
\end{abstract}

Palabras-Clave: Estado. Desarrollo. Argentina.

\section{¿POST-NEOLIBERAL STATE AND DEVELOPMENT IN LATIN AMERICA? A STUDY OF THE ARGENTINIAN CASE}

\section{ABSTRACT}

At the end of the last century, the States in Latin America have undergone a process of transformations in their organizational form and in their implicative logic towards the industrial productive sector, which have led to changes in the strategies of capital accumulation in the region, sharpening its peripheral position. Given this scenario, at the beginning of the 21st century, a series of neo-developmental reactions began to emerge. They sought to consolidate more virtuous accumulation strategies, sustaining a more inclusive and equalizing development. Have these reactions been able to advance in the conformation of an alternative State to the neoliberal one that allows these accumulation strategies to be viable? The work seeks to explore this question by analyzing the evolution of the organizational forms and the logics of implication of the Argentinian State, a paradigmatic case in the region of both neoliberal experimentation and neo-developmentalist reactions. The studies show the presence of cosmetic changes in the state configuration and its implicative logic in the productive industrial sphere, which did not allow to qualify the dynamics of domestic accumulation.

Keywords: State. Development. Argentina

\footnotetext{
${ }^{1}$ Doctor en Ciencias Políticas pela Universidad Autónoma de Madrid, España. Director do Instituto de Humanidades y Ciencias Sociales del Litoral (Ihucso Litoral). Profesor de la Universidad Nacional del Litoral (UNL), Santa Fe, Argentina.rfernand@fcjs.unl.edu.ar

2 Doctoranda en Ciencias Sociales pela Universidad de Buenos Aires. Magíster en Historia Económica y Política Económica pela Universidad de Buenos Aires. Docente-Investigadora de la Universidad Nacional del Litoral (UNL), Santa Fe, Argentina. clauxmann@hotmail.com
} 
La necesidad de recomponer el dinamismo de la acumulación capitalista sobre finales de la década del 60 del siglo pasado, hizo que comenzaran a experimentarse modificaciones en las estrategias estructurantes de la reproducción del capital a escala global que venían imperando desde la posguerra (GORDON; WEISSKOPF; BOWLES, 1987; HARVEY, 2007). Este cambio en las estrategias reproductivas fue habilitado por transformaciones en la conformación organizacional e implicativa de los diferentes Estados de la economía-mundo capitalista. De la mano de procesos de privatización, apertura, desregulación de mercados y descentralización, los Estados nacionales, muchos influenciados $y / o$ condicionados por organismos internacionales que proponían un programa de re-estructuración de claro corte neo-liberal (BIERSTEKER, 1990; BRENNER; PECK; THEODORE, 2011), viabilizaron la conformación de una economía capitalista cada vez más integrada - en tiempo y en espacio - a través de las estrategias de transnacionalización de la producción y las finanzas (CASTELLS, 1990; DICKEN, 1998; GEREFFI; KORZENIEWICZ, 1994).

América Latina ha sido uno de los espacios que más fuertemente vivenció estos cambios (ver por ejemplo SADER, 2008a, 2008b, 2009). A través de los procesos precedentemente referenciados, diversos Estados nacionales de la región experimentaron a) una reducción de las instancias vinculadas a la planificación y promoción de la actividad productiva industrial - que se venían consolidando desde la salida de la segunda posguerra - y b) cambios en la forma de implicación en dicha área, que terminaron posicionando a los mecanismos de mercado y a la actividad privada en un lugar preponderante en la definición del desenvolvimiento del sector (FERNÁNDEZ; CARDOZO, 2012; FERNÁNDEZ; GARCÍA PUENTE, 2012; OCAMPO; ROS, 2011). La ausencia de un aparato estatal que planifique y condicione la acumulación industrial dio lugar a la preeminencia de las lógicas transnacionalizadas de reproducción del capital global -financiero y productivo- en la estructuración del sector. Se produjo, así, una fuerte reducción, desarticulación y primarización del tejido industrial en la gran mayoría de los países de la región que habían logrado cierto progreso en esa área durante el periodo de posguerra. El desenvolvimiento del sector manufacturero quedó, así, limitado a actividades de baja sofisticación y capacidad de agregación de valor, asociadas a la explotación de las ventajas comparativas estáticas - de los recursos naturales y/o de la mano de obra barata-, que resultaban beneficiosas para la configuración de las cadenas globales de producción (ARCEO, 2005, 2011; KATZ, 2001).

Estas transformaciones en las formas de reproducción del capital al interior de los países latinoamericanos atentaron contra el dinamismo, la sostenibilidad e inclusividad de su crecimiento (PORTES; HOFFMAN, 2003), al mismo tiempo que propiciaron un incremento de la brecha de productividad e ingreso existente con los países centrales (ARRIGHI, SILVER; BREWER, 2003; MAHUTGA, 2006), reforzando su posicionamiento periférico.

Las consecuencias negativas que importaba para Latinoamérica este nuevo esquema reproductivo global fueron enfrentadas por diversas reacciones preocupadas por mejorar los patrones de reproducción social de la población (SADER, 2008a, 2008b, 2009). Desde inicios del siglo 21, una serie de gobiernos progresistas - vinculados a planteamientos de izquierda y/o centro-izquierda - accedieron al Estado en distintos países de América Latina y plantearon - al menos en el plano discursivo - la necesidad 
de conformar una estrategia reproductiva alternativa-superadora - a la vigente, que permitiera salir de la periferia y viabilizar el desarrollo de la región. Para procurar este cometido, la re-intervención estatal en la regulación de la economía, aún con especificidades en los diferentes países, ha sido un elemento común en el escenario latinoamericano (ver por ejemplo: ARANÍBAR; RODRÍGUEZ, 2013; BRESSER-PEREIRA, 2007, 2006; GRUGEL; RIGGIROZZI, 2012; SADER, 2009).

Así como la re-estructuración y los cambios en las modalidades de implicación del Estado-Nación han sido centrales en la viabilización de las estrategias de acumulación estructurantes de la reproducción capitalista a fines del siglo pasado, la construcción de un nuevo tipo de Estado o, más específicamente, de un proyecto estatal (JESSOP, 1990), resulta esencial en la configuración de una estrategia de acumulación alternativa. Pero, ¿̇hasta qué punto se ha podido prosperar en la conformación de un Estado que, sobre la base de la recomposición y recualificación del sector industrial, contribuya a consolidar un patrón de acumulación dinámico, sostenible e inclusivo que viabilice el desarrollo?3 Para procurar dar respuesta a esta pregunta vamos a adentrarnos en el estudio del caso argentino, en tanto resulta uno de los más paradigmáticos del escenario latinoamericano en lo que hace a la contrastante experimentación, primero, de la conformación de un proyecto estatal neo-liberal (EVANS, 2004), y, luego, más recientemente, de los intentos de configuración de proyecto reactivo al mismo (ver por ejemplo ARANÍBAR; RODRÍGUEZ, 2013).

Para avanzar en el desarrollo de los distintos puntos planteados en esta introducción el trabajo se estructura de la siguiente manera. Se presenta un primer apartado en el que se presta especial atención al proyecto estatal configurado sobre finales del siglo pasado a escala global -al que vamos a denominar neoliberal - aunque poniendo particular énfasis en lo sucedido a este respecto en la periferia latinoamericana. Se continúa, luego, en el segundo apartado, con el análisis de las características de las reacciones neodesarrollistas emergentes en América Latina a partir de los resultados socio-económicamente negativos de las estrategias acumulativas a que habilitó el proyecto estatal neoliberal.

En el tercer apartado, a partir del estudio del caso argentino, se procura indagar hasta qué punto se ha podido avanzar en la configuración de un proyecto estatal superador del neoliberal que permita habilitar una estrategia de acumulación que viabilice la salida de posicionamientos periféricos. Se indagan aquí las continuidades y/o disrupciones que el Estado-Nación ha sufrido en su estructura organizacional y lógica implicativa entre fines del siglo pasado, de primacía neoliberal, e inicios del presente bajo las reacciones neodesarrollistas. Los resultados arrojan la presencia de cambios cosmésticos en

\footnotetext{
${ }^{3}$ La discusión sobre la necesidad de configurar un sector manufacturero para viabilizar procesos de desarrollo es tema de investigación específica que excede los límites del presente trabajo. El lector interesado en el tema puede consultar la siguiente literatura: AMSDEN, A. La sustitución de importaciones en las industrias de alta tecnología: Prebisch renace en Asia. CEPAL, 82, p. 75-90. 2004; AMSDEN, A. The rise of the Rest: Challenges to the West from the Late-Industrializing Economies. New York: Oxford University Press. 2001; HIKINO, T.; AMSDEN A. La industrialización tardía en perspectiva histórica, Desarrollo Económico, 35, p 3-34. 1995; SZIRMAI, A; NAUDE, W.; ALCORTA, L.(Eds.) Pathways to Industrialization in the Twenty-First Century. New Challenges and Emerging Paradigms. Great Britain: Oxford University Press, 2013
} 
la configuración organizacional y las lógicas de implicación del Estado-Nación en la faz productiva industrial, los que no permitieron cualificar las dinámicas de acumulación domésticas.

Para concluir, se retoman articuladamente los distintos puntos desarrollados en el trabajo y se presentan unas breves consideraciones finales.

\section{EL PROYECTO ESTATAL NEOLIBERAL Y LA DINÁMICA DE ACUMULACIÓN DEL CAPITAL \\ En el Escenario Global y en la Periferia Latinoamericana}

Los Estados ocupan un rol central en la viabilización del proceso de acumulación, habilitando distintas estrategias de valorización del capital. Asumiendo particulares formas organizativas e implicativas, en el marco de una disputada relación de clases, fracciones, grupos y movimientos sociales, los Estados cristalizan una estrategia política, y pasan a constituirse en un proyecto estatal (JESSOP, 1990) habilitante de diferentes modalidades de acumulación capitalista, con patrones más o menos equitativos de reproducción social a ella asociados.

Durante las últimas décadas del siglo pasado los Estados presentaron una particular estructura organizacional e implicativa que viabilizó una estrategia de acumulación del capital - productivo y financiero - que opera a nivel global - involucrando a una multiplicidad de espacios, escalas y actores (JESSOP, 1999, 2013a, 2013b) y en tiempo real (CASTELLS, 1990).

El surgimiento de esta nueva estrategia de acumulación se encontraba asociado a la necesidad de recomponer la tasa de ganancia, que estaba viéndose erosionada sobre finales de la década de 1960 (CROTTY, 2000; GORDON; WEISSKOPF; BOWLES 1987; JESSOP, 1999; KOTZ, 2008). Los avances en la ciencia y la tecnología - fundamentalmente aplicados a la informática y las comunicaciones - fueron centrales para posibilitar la misma (BALDWIN, 2011). A través de la "revolución tecnológica", que tuvo lugar durante las últimas décadas del siglo 20, se ha podido comprimir fuertemente el espacio por el tiempo (HARVEY, 1998) y conformar redes de producción globales que integran funcionalmente - en tiempo real- actividades dispersas en distintos espacios nacionales y dan como resultado una panoplia bienes y/o servicios (DICKEN, 1998; GEREFFI; KORZENIEWICZ, 1994). Los desarrollos tecnológicos posibilitaron, asimismo, la generación de nuevos instrumentos financieros para la valorización del capital que hicieron posible que la reproducción capitalista tenga lugar crecientemente bajo formas financiarizadas ${ }^{4}$ (EPSTEIN, 2005; KOTZ, 2008), incluso dentro de dichas redes globales de producción (LAZONICK, 2013; MILBERG, 2008; PALMA, 2009; STOCKHAMMER, 2009).

\footnotetext{
${ }^{4}$ Las formas financieras de valorización del capital se caracterizan por presentar un horizonte temporal de realización mucho más reducido que aquel asociado a la producción, dando lugar a la preeminencia de una forma de valorización del tipo D-D' antes que D-M-D', en donde, siguiendo la fórmula general del capital presentada por Marx, D representa al capital-dinero, que significa liquidez, flexibilidad y libertad de elección; $M$ al capital-mercancía, que simboliza al capital invertido en una determina combinación input-output no como un fin en sí mismo, sino como un medio para la reproducción ampliada del capital-dinero y D' al capital-dinero ampliado, que es sinónimo de liquidez, flexibilidad y libertad de elección expandidas.
} 
Las nuevas estrategias de reproducción fueron adquiriendo una centralidad estructurante de las relaciones de producción capitalista a escala planetaria en la medida en que se fue avanzando en la redefinición organizacional e implicativa de los Estados-Nación, habilitantes de las mismas. Procesos de privatización, apertura, desregulación de mercados y descentralización, impulsados por actores endógenos a los espacios nacionales, pero a instancia de organismos internacionales que proponían y/o imponían un programa de re-estructuración de claro corte neoliberalizador (BIERSTEKER, 1990; BRENNER; PECK; THEODORE, 2011; COX, 1993), tuvieron lugar en gran parte de la economía mundo, afectando particularmente a la periferia latinoamericana (GAITÁN, 2013; SADER, 2008a).

En este contexto de expansión de la disciplina del mercado a esferas de la vida socio-económica que antes se hallaban ajenas a la mercantilización, los Estados latinoamericanos, en relación a su intervención en el ámbito de la acumulación, redujeron y desfinanciaron las estructuras destinadas a planificar y promover el desarrollo de la actividad productiva-industrial al interior del ámbito nacional, y modificaron su forma de implicación en el sector (FERNÁNDEZ; CARDOZO, 2012; FERNÁNDEZ; GARCÍA PUENTE, 2012; GAITÁN, 2013; OCAMPO; ROS, 2011). Al mismo tiempo, mantuvieron y/o incrementaron su participación en materia de legitimación social (CEPAL, 2004) - aunque con un carácter crecientemente focalizado (LACABANA; MAINGON, 1997; GAITÁN, 2013) - a fin de brindar soporte a estas nuevas formas de acumulación socio-espacialmente excluyentes y marginadoras.

La nueva estrategia de reproducción global del capital ya no requería una planificación estatal y apoyo a la conformación de industrias verticalmente integradas y burocráticamente administradas de base nacional, como durante la posguerra (ARRIGHI, 1999). Esta demandaba la posibilidad de organizar e integrar funcionalmente diferentes actividades localizadas en distintos espacios nacionales -aprovechando las ventajas de costos que le proporcionaban las mismas- en redes de producción global que operan en tiempo real, y/o de ejecutar estrategias de valorización financiera, para lo cual la posibilidad de un ingreso - y salida - libre e irrestricto de los capitales globales y la aplicación de políticas productivistas de apoyo a las actividades localmente competitivas resultaba central.

Debido a las ventajas comparativas que ofrecían gran parte de los países de la periferia latinoamericana - asociadas a la particular dotación de recursos naturales o mano de obra barata, con distinto niveles de calificación (ARCEO, 2011) - las nuevas lógicas reproductivas no sólo quitaron relevancia a la producción industrial de base nacional como estrategia estructurante de la acumulación de capital, sino que ocasionaron un fuerte deterioro - reprimarizante y desarticulador - de la matriz productiva industrial de estos países, con una fuerte pérdida y precarización laboral (ARCEO, 2011; KATZ, 2001). Sólo ciertas actividades poco cualificadas para la generación de desarrollo tecnológico endógeno y encadenamientos productivos, localizadas en espacios regionales - subnacionales - específicos, resultaban parte de las estrategias estructurantes de la acumulación a nivel sistémico y motorizaron las economías internas; el resto de los sectores, actores y espacios comenzaron a quedar relegados dentro de las lógicas de acumulación. 
Pero, las transformaciones en las estructuras productivas de los diferentes países de América Latina, sobre la base de la degradación cuanti y cualitativa del sector industrial, no respondieron solo a la reconfiguración de la producción a nivel global; las lógicas de valorización financiera del capital imperantes durante las últimas décadas del siglo pasado también ocuparon un papel relevante en dicho proceso. Mientras que para 1993 la IED era de US\$7.000 millones anuales, para inicios del siglo 21 esta pasó a ser superior a los US\$90.000; inversión que no se tradujo en aumento de capital físico sino que se destinó, en parte significativa, a actividades especulativas - como ser la compra de títulos de renta fija de alta rentabilidad (bonos de deuda pública) y/o a la adquisición de empresas - muchas de ellas públicas - ya existentes, con la venta de cuyas acciones, luego, se especulaba en el mercado (LIBREROS; CARRERO, 2014).

Vemos así que, el proyecto estatal neoliberal, a través de la liberalización y la desregulación importó una desimplicación del Estado en el direccionamiento y promoción del sector industrial, que viabilizó lógicas de acumulación internas que agravaron los problemas de sostenibilidad e inclusividad en el crecimiento y dieron lugar a un marcado deterioro socio-económico (PORTES; HOFFMAN, 2003).

Ante dicho contexto, no es de extrañar que diferentes reacciones a los efectos socio-económicos negativos habilitados por el proyecto estatal neoliberal emergieran en distintos países de la región (SADER, 2008a, 2009).

\section{LAS REACCIONES NEODESARROLLISTAS. SUS LIMITACIONES Y LA IMPORTANCIA DE AVANZAR EN LA CONFIGURACIÓN DE UN PROYECTO ESTATAL ALTERNATIVO-SUPERADO AL NEOLIBERAL}

Estas reacciones, denominadas por diversos autores como neo-desarrollistas (ver por ejemplo: ARANÍBAR; RODRÍGUEZ, 2013; BRESSER-PEREIRA, 2007, 2006; GAITÁN, 2014), evidenciaron particularidades en los distintos países de América Latina en los que tuvieron lugar (ARANÍBAR; RODRÍGUEZ, 2013; GRUGEL; RIGGIROZZI, 2012; SADER, 2009; YATES; BAKKER, 2013), pero también repararon en un elemento estratégico común: la re-implicación regulatoria del Estado en la re-dinamización de la actividad económica. Gran parte de los Estados latinoamericanos, procurando no descuidar la estabilidad de la economía, mejoraron la performance socio-económica de sus países a través de políticas macroeconómicas y de políticas sociales activas - redistributivas - que tenían como objeto estimular la demanda y el mercado interno (ARANÍBAR; RODRÍGUEZ, 2013; GRUGEL; RIGGIROZZI, 2012). Algunos países, incluso, también hicieron uso de herramientas para estimular la actividad productiva de exportación, e incorporar a la comercialización internacional de recursos naturales - con demanda creciente a nivel internacional y precios excepcionales - la de bienes manufacturaros de mayor valor agregado (ARANÍBAR; RODRÍGUEZ, 2013; BRESSER-PEREIRA, 2007, 2006; GAITÁN, 2013). Un lugar importante ocupó, también, en la agenda neo-desarrollista de la región la re-estatización de industrias estratégicas, fundamentalmente en los sectores energéticos y mineros (ARANÍBAR; RODRIGUEZ, 2013; GAITÁN, 2013; GRUGEL; RIGGIROZZI, 2012).

Pero las reacciones y sus políticas se han mostrado insuficientes en cuanto a la posibilidad de generar estrategias de acumulación domésticas dinámicas, sostenibles y equitativas, que modifiquen las condiciones de reproducción social de su población. 
La ausencia de una transformación estructural que tienda a recomponer el sector manufacturero - devastado por las políticas neoliberales - y a posicionarlo como motorizador del desarrollo, resulta un elemento central que no se encuentra dentro de las conquistas de estos proyectos políticos y sociales neodesarrolllistas.

Advirtiendo, como hemos planteado precedentemente, la importancia de la configuración del proyecto estatal neoliberal para habilitar la penetración de las lógicas de acumulación motorizadas por el capital transnacional en los diferentes espacios de la periferia latinoamericana; la ausencia de una transformación productiva que tienda a modificar los patrones reproducción socio-económicos internos puede explicarse a partir de la inexistencia de un cambio cualitativo en la organización y en las formas de implicación estatal, particularmente en lo que refiere al ámbito productivo industrial.

A continuación vamos a analizar las continuidades y/o disrupciones en la configuración organizativa y lógica implicativa del Estado-Nación Argentino, en tanto resulta uno de los más paradigmáticos del escenario latinoamericano en lo que hace a la contrastante experimentación, primero, de la conformación de un proyecto estatal neo-liberal, y, luego, más recientemente, de los intentos de configuración de proyecto neodesarrollista reactivo al mismo.

\section{EL ESTADO ARGENTINO ENTRE LA RECONFIGURACIÓN NEOLIBERAL Y LAS REACCIONES NEODESARROLLISTAS}

\section{El Estado Neoliberal Argentino (1989-2001)}

Durante la década de 1990 la estructura socio-económica y política de Argentina sufrió fuertes modificaciones. En dicho proceso de transformaciones, la reconfiguración del Estado ocupó un lugar central, no sólo por el peso en sí misma, sino porque viabilizó un cambio en las lógicas de acumulación domésticas, haciéndolas más permeables a los intereses y lógicas de las fracciones transnacionalizadas del capital. El aparato estatal, como resultado de una estrategia política -configurada en el marco de disputas de clases, fracciones, grupos y movimientos sociales-, modificó su estructura organizacional y sus formas implicativas, conformando una arquitectura institucional viabilizadora de una nueva estrategia de acumulación motorizada por las fracciones del capital global a nivel interno. Diversas han sido las modificaciones que en este sentido experimentó el Estado-Nación a lo largo de los 90s. Procuramos dar cuenta de ellas a través de un análisis de la evolución de su esquema ministerial, sus particulares funciones y competencias, y del nivel de gasto público, así como de las formas de implicación del Estado a partir de este esquema organizativo.

A nivel estructural, en primer lugar, es posible advertir una jibarización del aparato estatal. El esquema ministerial del Estado nacional presentó una reducción de su tamaño en comparación al existente con anterioridad al inicio del proceso de reformas. Las Leyes de Emergencia Económica (Ley $N^{\circ} 23.697$ ) y de Reforma del Estado (Ley $\mathrm{N}^{\circ}$ 23.696) sentaron las bases para esta transformación del Estado en línea a conformar un proyecto estatal neoliberal. Luego de haber transitado varias décadas de intervencionismo estatal en el desenvolvimiento socio-económico - desde mediados del siglo 20 - y habiéndose obtenido resultados limitados en términos de crecimiento económico y desarrollo, numerosos académicos y policy makers locales, influenciados por la creciente 
hegemonía neoliberal que estaba consolidándose a nivel global, y que se institucionalizaba en el discurso de prestigiosos tanques de pensamiento internacionales (BIERSTEKER, 1990; BRENNER; PECK; THEODORE, 2011; COX, 1993), sindicaron como principal causa de los mismos a la ineficiencia del Estado y a los comportamientos rentistas y clientelares que este habilitaba (CAVAROZZI, 1991; FERNÁNDEZ; TEALDO; VILLALBA, 2005; LLACH, 1997). De esta manera, con impulso interno, pero a instancia de los organismos internacionales de tendencia neoliberalizadora - como el BM, BID, FMI -, a través de las precitadas leyes, se propició una reconfiguración del Estado-Nación que justificó su des-implicación de la regulación de la actividad económica, reservándose sólo las prestaciones - no delegadas a las provincias- de servicios públicos esenciales para el desenvolvimiento social (INAP, 1997).

Si analizamos la estructura organizativa del aparato estatal y sus asignaciones presupuestarias podemos dar cuenta de dichas transformaciones. En lo que refiere al organigrama del Estado, se advierte una reducción del número de instancias ministeriales, secretarías y subsecretarías vinculadas a la regulación del sistema económico y a la actividad económica del sector público. Según el Decreto $N^{\circ} 355 / 89$, que establecía la organización de la estructura ministerial con anterioridad a la puesta en marcha del proceso de Reforma del Estado, las instancias centralmente vinculadas a la actividad económica tenían una importancia significativa dentro del aparato estatal. El Ministerio de Economía contaba con 8 Secretarías y 20 Subsecretarías, y el Ministerio de Obras y Servicios Públicos tenía designadas 4 Secretarías y 11 Subsecretarías para cumplir sus funciones, lo que representaba, en conjunto, cerca del $48 \%$ de las agencias estatales vigentes. Puesto en marcha el precitado proceso de ajuste, ambos Ministerios redujeron drásticamente el número de dependencias con que contaban para desenvolver su actividad; el Ministerio de Economía pasó a tener sólo 7 Subsecretarias y el Ministerio de Obras y Servicios Públicos 4, con lo cual su participación dentro del total de reparticiones dentro organigrama estatal descendió aproximadamente al 34\% (ver Anexo I).

Dichas modificaciones significaron una verdadera des-implicación estatal en el área económica, particularmente en el impulso de la actividad productivo-industrial. El análisis de la evolución del volumen del gasto público refuerza esta interpretación. En un contexto general de expansión del gasto total del Estado-Nación argentino, la finalidad servicios económicos experimentó un franco deterioro; pasó de representar el 8,87\% del gasto total en 1994 a significar sólo el 3,9\% del mismo en 2001 (Gráfico 1). La pérdida de gravitación de esta finalidad se hace aún más notoria cuando se la compara con el volumen de gasto en servicios económicos promedio para la década de 1980 (27,32\%). Algo similar ocurre al observar la evolución de la función industria -dentro de la finalidad servicios económicos-; si bien esta nunca alcanzó valores significativos dentro del presupuesto estatal, en promedio para la década de 1980 rondaba el 1,6\% del mismo, durante los 90 s su participación se redujo progresivamente llegando a valores bien por debajo del punto porcentual (Gráfico 1). 
Gráfico 1 - Evolución del Gasto Público Nacional Total: valores corrientes y Participación de los Servicios Económicos (finalidad) e Industria (función) en el Total

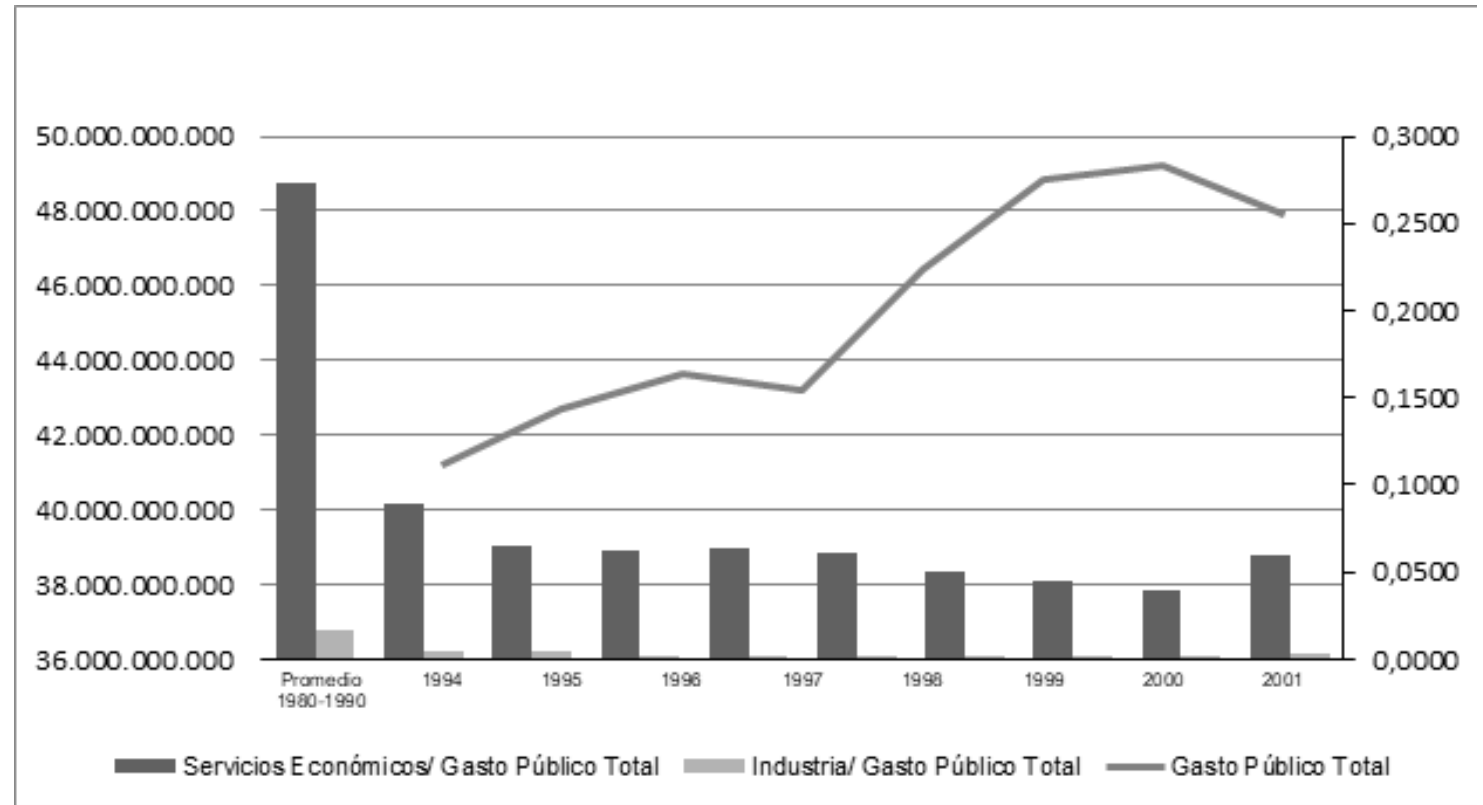

Fuente: Elaboración propia en base a datos de la Oficina Nacional de Presupuesto del Ministerio de Economía de la Nación y la Dirección de Análisis de Gasto Público y Programas Sociales de la Secretaría de Política Económica.

Es importante mencionar que, además de la pérdida de centralidad dentro de la estructura estatal de las instancias - directa e indirectamente - vinculadas a la actividad económica - y la pérdida de gravitación del Estado-Nación en dicha esfera que ello refleja -, las formas de implicación estatal en el área sufrieron importantes modificaciones con relación al período interventivo estado-céntrico de la ISI. Particularmente en lo que respecta al área de promoción industrial, el Estado pasó de desarrollar programas de apoyo productivo nacionalmente concebidos y con objetivos de desarrollo equilibrado e integral del territorio nacional (CORDONE, 2004; ROFMAN, 1981), a implementar políticas fragmentarias que incentivaban la asociación de determinados actores, muchos de ellos aglomerados en espacios sub-nacionales específicos (ver por ejemplo RAMOS, 1998; KANTIS, 2005).

Este cambio organizacional y funcional del Estado tuvo consecuencias en las formas de acumulación y reproducción del capital al interior de las fronteras nacionales. La reestructuración estatal habilitó la penetración de las fracciones transnacionalizadas del capital y sus lógicas de reproducción tanto en la esfera productiva -asociadas a la explotación de ventajas comparativas de los recursos naturales o "institucionales de privilegio" (AZPIAZU; SCHORR, 2010) como financiera, en actividades crecientemente especulativas (BASUALDO, 2000). Ello trajo como consecuencia el deterioro de la estructura industrial que se había consolidado - con sus limitaciones y falencias - durante la etapa de ISI, y habilitó la conformación de un patrón de acumulación altamente concentrado - socio-espacialmente - inestable, restrictivo y excluyente, que reforzó las asimetrías internas y el posicionamiento periférico del país (ver AZPIAZU; SCHORR, 2010; BASUALDO, 2000; MANZANAL, 1995; ROFMAN, 1999, 2000).

Ante este escenario de crecimiento restringido y empobrecedor de una gran proporción de la población, con el devenir de la década de 1990, el Estado incrementó su intervención en el área de legitimación social. Ello se ve reflejado a nivel organizativo, 
presupuestario y funcional. A nivel de la estructura del Estado, la creciente importancia de la política social comenzó a visibilizarse con la creación de la Secretaría de Desarrollo Social dependiente de la Presidencia de la Nación, a partir de la escisión del área social del Ministerio de Salud y Acción Social (a través del decreto $N^{\circ} 227 / 94$ ), y luego se convalidó y reforzó, con la conformación del Ministerio de Desarrollo Social y Medio Ambiente, a través de la Ley $\mathrm{N}^{\circ} 25.233 .{ }^{5}$ Este cambio en la estructura estatal vinculada al área de legitimación social fue acompañado por una alteración en el "poder de fuego" asignado a la misma. El gasto del Estado en materia social pasó de un valor promedio cercano al 45\% del gasto total en la década de 1980, según información de la Dirección de Análisis de Gasto Público y Programas Sociales de la Secretaría de Política Económica, a promediar más del 61\% del total del gasto entre 1993 y 2001 (Gráfico 2).

Gráfico 2 - Evolución del Gasto Social en Relación al Gasto Total del Estado-Nación (1993-2001)

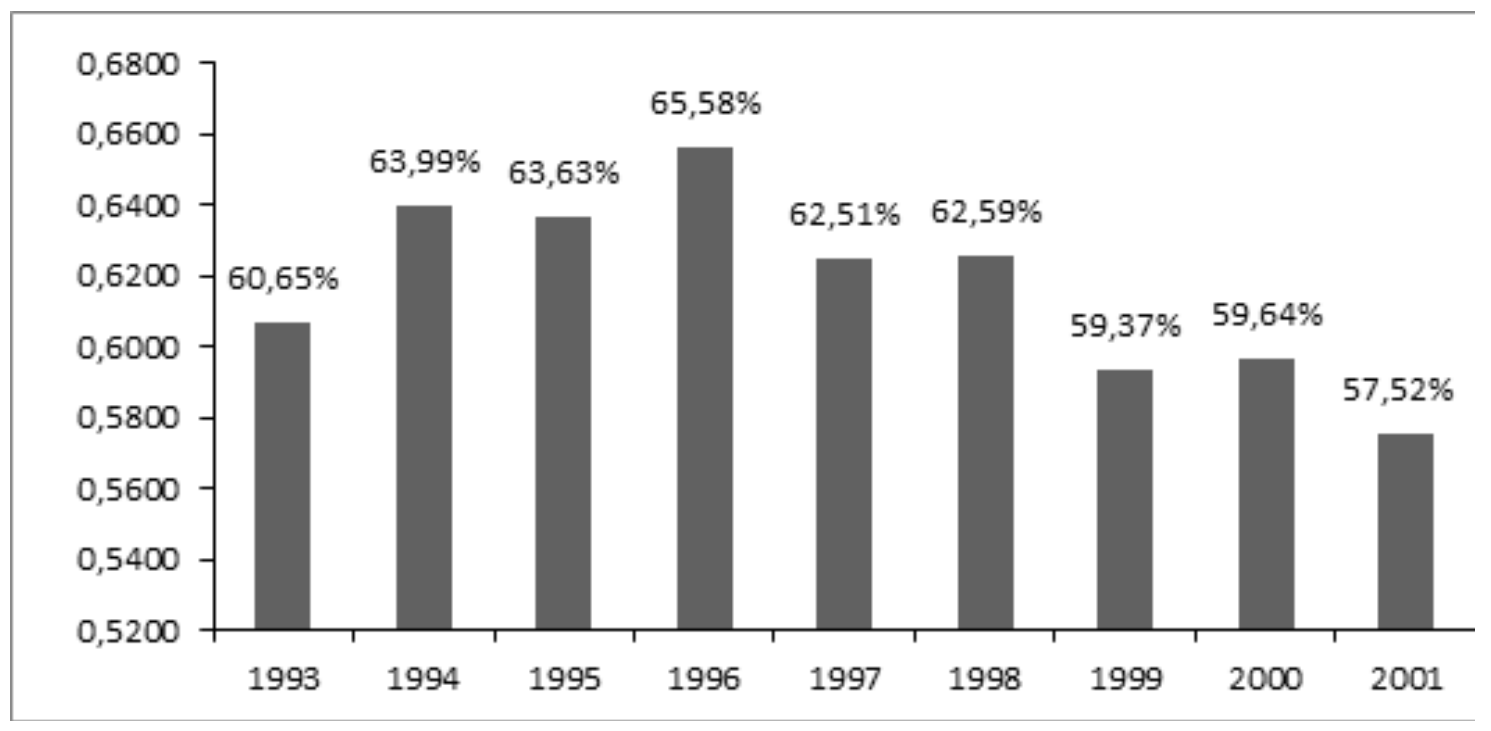

Fuente: Elaboración propia en base a datos de la Oficina Nacional de Presupuesto del Ministerio de Economía de la Nación.

Pero no sólo la estructura y el poder de fuego del Estado en el área de legitimación social se vieron modificadas, también se experimentaron cambios en la forma de implicación estatal a la hora de cumplir con sus metas y objetivos en esta esfera. Particularmente, a este respecto, resulta relevante destacar la progresiva focalización de la política social, dejando atrás un esquema previo más abarcativo y universalizador propio del periodo de ISI (LACABANA; MAINGON, 1997; LÓPEZ, 2003; PAUTASSI, 2013; REPETTO; POTENZA DAL MASETTO, 2011; SOLDANO; ANDRENACCI, 2006). Esta modificación la dotó de un carácter meramente paliativo, antes que integrador e incluyente, y, por lo tanto, limitado para hacer frente a los crecientes problemas de marginalidad existentes.

Vemos así cómo el proceso de cambios experimentado por el Estado-Nación a lo largo de la década de 1990 importó: a) la desvinculación estatal del área de servicios económicos-productivos, manteniendo sólo una remanente participación marginal en

\footnotetext{
5 La precitada Ley sancionada el 10 de Diciembre de 1999 modificó la Ley de Ministerios y creó el Ministerio de Desarrollo Social y Medio Ambiente a partir de la unión de las ex Secretarías de: Desarrollo Social; Recursos Naturales y Desarrollo Sustentable; y Deportes, que operaban en la esfera de la Presidencia de la Nación (LÓPEZ, 2003).
} 
la misma a través de políticas que incentivaban una selectiva y excluyente asociación de ciertos actores - muchos aglomerados en determinados espacios subnacionales $-b$ ) una creciente participación - con carácter fragmentado y focalizado - en el área de gastos sociales, ante las presiones de legitimidad política y la necesidad de contener al creciente porcentaje de la población en condiciones de pauperización, a fin de viabilizar la continuidad de estas formas excluyentes de reproducción social a que incitan las lógicas de acumulación impulsadas por las fracciones transnacionalidades del capital.

El sostenimiento y viabilización de la reproducción capitalista por la vía de la legitimación, antes que a través de un apuntalamiento - directo o indirecto - a la conformación de una lógica de acumulación que sea más dinámicas, sostenidas e inclusivas, comenzó a evidenciar sus limitaciones ya en los últimos años de la década de 1990. Desde 1998 la economía argentina comenzó a atravesar una fase recesiva, que para 2001 se tradujo en una caída de más del 20\% del Producto, índices de desempleo superiores al $21 \%$ y niveles de pobreza que alcanzaron al $53 \%$ de la población total.

La insostenibilidad del proyecto estatal neoliberal para moderar las contradicciones propias de la reproducción capitalista bajo estas lógicas transnacionalizadas de acumulación y viabilizar con cierta legitimidad su desenvolvimiento interpeló a la búsqueda de nuevas formas acumulativas y proyectos estatales que las habiliten. Apelando a una retórica "desarrollista", los gobiernos que asumieron tras la crisis de 2001, al igual que gran parte de los gobiernos de centro izquierda de la región, apostaron a un fuerte apuntalamiento estatal para recomponer el dinamismo de la economía. Particularmente, para el caso de argentino, se hizo un fuerte hincapié en la re-intervención del Estado en la re-composición del la actividad industrial - que tan afectada había resultado por la apertura, la desregulación y las privatizaciones -; se consideraba que a través de la misma se podría habilitar la conformación una estrategia acumulativa más virtuosa en términos de dinamismo, sostenibilidad e inclusividad (MINISTERIO INDUSTRIA, 2011).

Como mencionábamos para el escenario latinoamericano en general, vimos, para el caso argentino en particular, cómo la reconfiguración organizativa y funcional del Estado en los 90s fue parte central de una estrategia política para viabilizar, al interior del espacio nacional, con cierta coherencia y sostenibilidad la acumulación capitalista conforme a las lógicas impulsadas por las fracciones transnacionalizadas del capital global. Ahora bien, vamos a analizar, a través del estudio del mismo caso, ¿en qué medida se ha podido avanzar en la región en la configuración de un tipo de estatidad que, desde sus particulares estructuras y formas de implicación, contribuya a impulsar estrategias de acumulación domésticas que propicien el desarrollo? Procuramos dar respuesta a este interrogante en el aparatado siguiente.

\section{El Estado Neo-Desarrollista Argentino ¿Avances Hacia un Proyecto Estatal Post-Neoliberal que Viabilice el Desarrollo?}

Si bien resulta necesario reconocer la recomposición en la rítmica del crecimiento, y las reducciones en los niveles de pobreza que convivieron con una sensible disminución en los índices de desigualdad durante los primeros tiempos de las gestiones kirchneristas (VARESI, 2016). También es necesario plantear que a inicios de la segunda década de la centuria emergió un creciente cuerpo de problemas, muchos de los cuales estaban vinculados con la imposibilidad de avanzar en una transformación de la estructura productiva, que atentaron contra la sostenibilidad de los procesos de crecimiento con equidad distributiva. 
Siguiendo el planteo introducido en el presente trabajo, entendemos que esta inalteración en la estrategia acumulativa se encuentra asociada con la inexistencia de avances en la conformación de un proyecto estatal post-neoliberal. Para dar cuenta de la misma, a continuación, vamos a estudiar la evolución del esquema ministerial del Estado-Nación y las modalidades de implicación que se desprenden de la misma desde inicios de siglo 21.

A partir de la salida de la crisis de 2001 se puede observar cómo el aparato estatal ha ido expandiendo las estructuras vinculadas a la esfera económica. El organigrama del Estado Nacional muestra una proliferación ${ }^{6}$ de instancias destinadas al fomento de la actividad económica (ver anexo l), en línea con la intención de los gobiernos imperantes desde 2003 de volver a implicar al Estado en el fomento de la actividad productiva-industrial para, a partir de ella, estimular un crecimiento dinámico, inclusivo y sostenido. No obstante, también puede advertirse que las secretarías y subsecretarías centralmente vinculadas a la regulación del sistema económico y a la actividad económica del sector público - que otra vez volvió a tener lugar a partir de la re-nacionalización de ciertas empresas, como Aerolíneas Argentinas e YPF - perdieron peso dentro de la estructura ministerial -que se expandió conjuntamente en distintas áreas- representando el 31,5\% del total de estas instancias - conforme esquema ministerial vigente sobre finales de la segunda presidencia de Cristina Fernández de Kirchner.

Asimismo, en lo que refiere al poder de fuego de estos Ministerios - con sus secretarías y subsecretarías - se observa que también perdieron relevancia en comparación con el período neoliberal, conforme a la clasificación institucional del Gasto Público Nacional, como surge del Gráfico 3.

Gráfico 3 - Evolución del Gasto Publico del Ministerio de Economía y Obras y Servicios Públicos y las sucesivas denominaciones y desagregaciones experimentados por el mismo durante el periodo 1993-2014, como porcentaje del gasto total

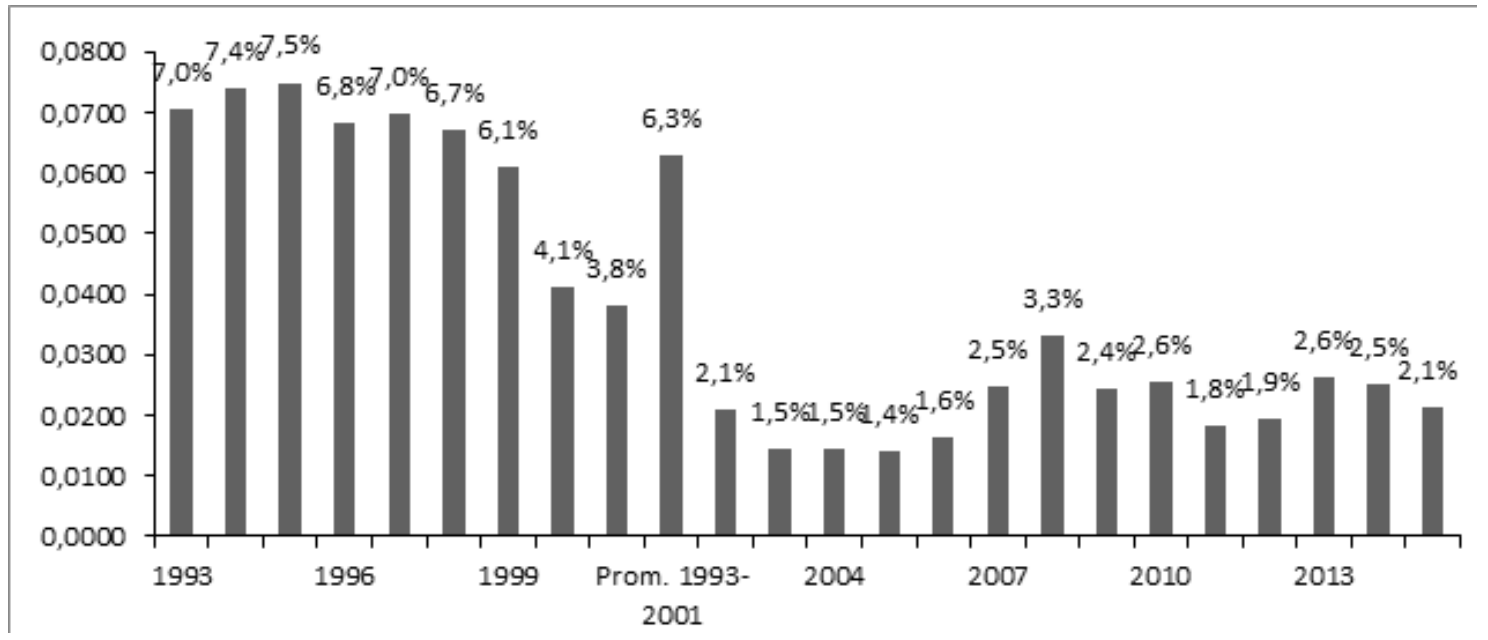

Fuente: Elaboración propia en base a datos de la Oficina Nacional de Presupuesto del Ministerio de Economía de la Nación.

\footnotetext{
${ }_{6}^{6}$ Por ejemplo a través de la desagregación del Ministerio de la Producción - creado por decreto 2025-08 - en los Ministerios de Industria y Ministerio de Agricultura, Ganadería y Pesca - Decreto N 1365-09 - para enfatizar la trascendencia que se considera tienen estas actividades productivas para el progreso y el desarrollo de la economía nacional y de la población en su conjunto.
} 
No obstante, cuando analizamos más allá de las instancias ministeriales que directamente estarían implicadas en la intervención en la esfera económica - que conforme al esquema vigente a la fecha antes mencionada involucra al: Ministerio de Economía y Finanzas Públicas; Ministerio de Planificación Federal, Inversión Pública y Servicios, Ministerio de Industria; Ministerio de Agricultura, Ganadería y Pesca y Ministerio de Turismo - y realizamos un análisis del gasto por funciones, podemos advertir un importante crecimiento de la participación de servicios económicos dentro del total del gasto público nacional (Gráfico 4). Sin embargo, cuando profundizamos el análisis al interior de la función, podemos observar (Gráfico 5) que los flujos destinados a la actividad industrial representan una participación relativa promedio inferior a la década del 90 . El grueso del gasto público de servicios económicos $(78,27 \%)$ estuvo destinado a subsidiar el consumo de electricidad y/o transporte, ${ }^{7}$ sin atender directamente al estímulo del desarrollo industrial.

Gráfico 4 - Gasto Público Nacional por finalidades, promedio para la década de 1990 y el periodo 2002-2014

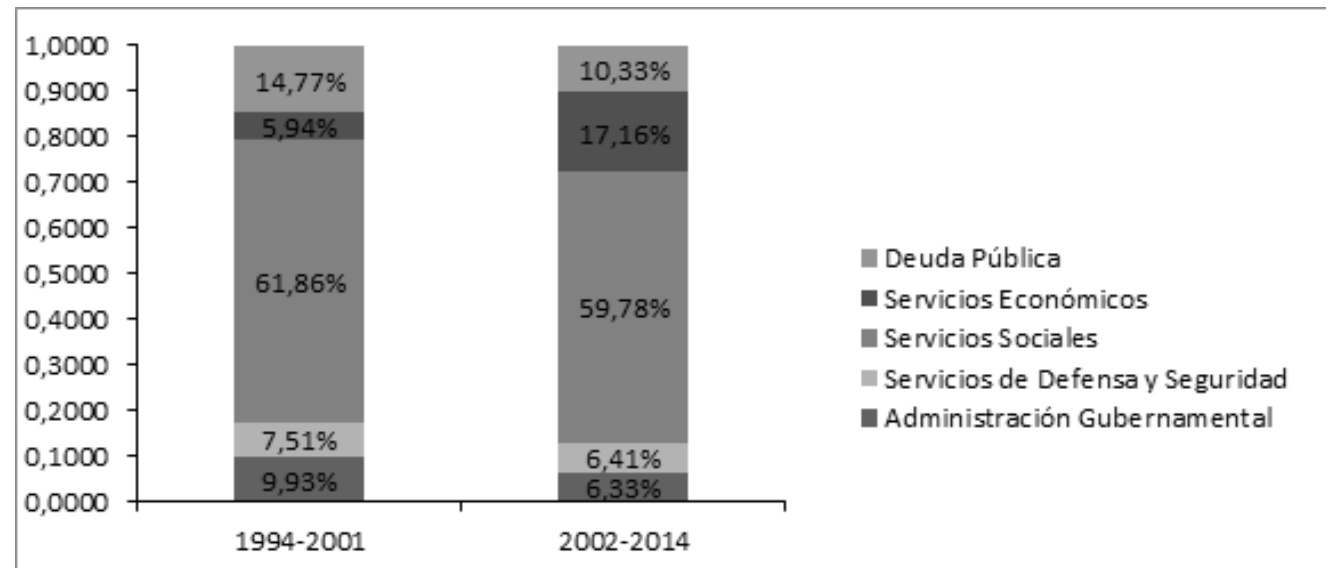

Fuente: Elaboración propia en base a datos de la Oficina Nacional de Presupuesto del Ministerio de Economía de la Nación.

Gráfico 5 - Gasto Público Nacional en Servicios económicos desagregado por funciones, promedio para la década de 1990 y el periodo 2002-2014

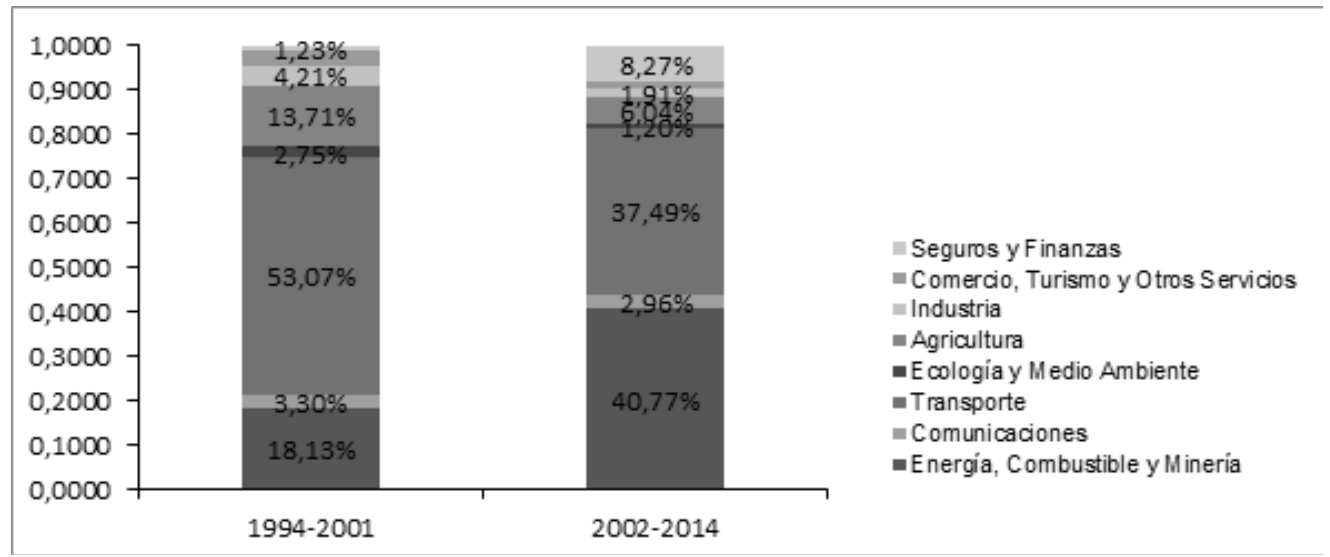

Fuente: Elaboración propia en base a datos de la Oficina Nacional de Presupuesto del Ministerio de Economía de la Nación.

\footnotetext{
7 Para dimensionar la incidencia de la política de subsidios dentro de la política del Estado Argentino ver por ejemplo Damill y Frenkel (2009).
} 
Por su parte, el gasto público social, aunque con la baja de dos puntos porcentuales con relación a los 90 s, continúa ocupando un lugar central dentro del gasto total del Estado Nacional (Gráfico 4), lo que habilita a apuntalar por vías desmercantilizadas los procesos acumulativos y a mitigar las consecuencias de exclusión y marginalidad que el mismo trae aparejado. La re-estatización de los fondos de jubilaciones y pensiones; la intención de re-centralizar la planificación estratégica de la prestación de servicios públicos descentralizados durante el decenio anterior - como salud y educación - así como el proyecto de dejar atrás el carácter focalizado de la política social - aunque aún se advierte una importante persistencia de las mismas (ver por ejemplo ARANÍBAR; RODRIGUEZ, 2013; GAITÁN, 2013; PAUTASSI, 2013) - y procurar que ésta re-adquiera mayor universalidad (REPETTO; POTENZA DAL MASETTO, 2011), son algunos de los elementos que permitirían explicar el incremento de este tipo de gasto en el Estado-Nación durante el período neodesarrollista (Gráfico 6).

Gráfico 6 - Evolución del Gasto Público Nacional en Servicios Sociales entre 2002-2014

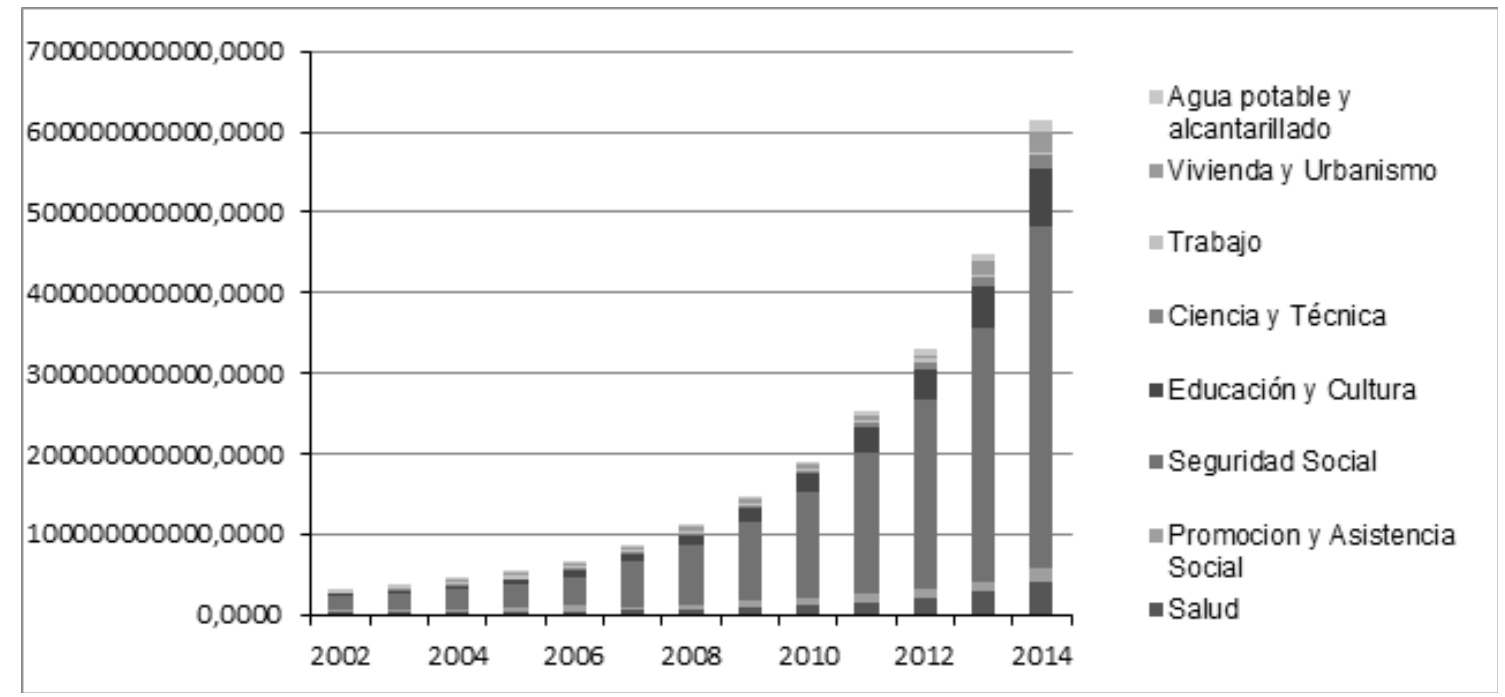

Fuente: Elaboración propia en base a datos de la Oficina Nacional de Presupuesto del Ministerio de Economía de la Nación.

Ante este estado de situación, podemos advertir que, pese al cambio en la concepción del rol del Estado en el desenvolvimiento económico y social post- crisis 2001, las transformaciones organizativas sufridas por el mismo y sus formas de implicación en los albores del siglo 21 permiten advertir la preeminencia de continuidades antes que cambios con relación al proyecto estatal neoliberal de la década de 1990 y, por ende, la falla en la conformación de una estatidad estratégica que habilite una lógica reproductiva del capital dinámica, sostenida e inclusiva que propicie el desarrollo.

No estamos ante un problema técnico de organización y funcionamiento eficiente del aparato del Estado, sino ante la incapacidad de avanzar en la disputa política - de clases, fracciones, grupos y/o movimientos sociales - hacia la configuración de un aparato estatal con ciertas propiedades organizativas e implicativas que habiliten formas acumulativas alternativas a las imperantes bajo el proyecto estatal neoliberal. Sólo algunas modificaciones "cosméticas" han operado en términos de la estructura y lógicas de implicación del Estado-Nación en la faz productiva industrial, las que no permitieron 
cualificar las dinámicas de acumulación domésticas. Dichos cambios superfluos fueron legitimados y habilitados por la persistencia de una significativa presencia de instancias vinculadas a la política y los gastos sociales.

\section{CONSIDERACIONES FINALES}

Las particulares formas estructurales e implicativas adoptadas por gran parte de los Estados-Nacionales de la economía-mundo capitalista sobre finales del siglo pasado habilitaron que las estrategias de reproducción capitalistas impulsadas por las fracciones transnacionalizadas del capital se convirtieran en las estructurantes de la acumulación a nivel global. Las lógicas de las redes globales de producción y los procesos de financiarización - que se configuraron de forma paralela pero también penetrando en las actividades productivas - importaron estrategias de acumulación capitalista fuertemente contradictorias y excluyentes que, para inicios del siglo presente, dieron lugar a un fuerte proceso de reacción que demandaba configurar proyectos estatales alternativos que restituyan cierto dinamismo y legitimidad a la reproducción del capital.

Esta reacción a nivel latinoamericano se vio plasmada en el acceso de distintos proyectos políticos y sociales de izquierda y centro-izquierda al Estado a través de procesos eleccionarios que tuvieron lugar a inicios del siglo 21. Si bien a nivel discursivo estos gobiernos apostaron a una re-intervención estratégica del Estado para dinamizar la actividad económica y moderar las inequidades sociales, han sido limitados los avances que han podido lograr en estas materias.

Sobre la base del análisis de la experiencia del paradigmático caso argentino, podemos advertir que sólo han tenido lugar algunas modificaciones cosméticas en la estructura y formas de implicación del Estado en la faz productiva-industrial, que no permitieron alternar las lógicas estructurantes de acumulación capitalistas impulsadas por las fracciones transnacionalizadas del capital que vienen moldeando los patrones acumulativos de la región desde fines del siglo pasado. Ello se sostuvo, en tanto persistieron, con una significativa presencia, instancias vinculadas a la política y los gastos sociales, que, operando a través de la legitimación, no hicieron imperioso avanzar en transformaciones sustantivas en las áreas productivas-industriales.

\section{REFERENCIAS}

ARANÍBAR, A.; RODRÍGUEZ, B. Latinoamérica ¿del neoliberalismo al neodesarrollismo? In: ARANÍBAR, A.; RODRÍGUEZ, B. (ed.). América Latina ¿del neoliberalismo al neodesarrollismo? Buenos Aires: Siglo XXI Editores, 2013.

ARCEO, E. El largo camino a la crisis. Centro, periferia y transformaciones en la economía mundial. Buenos Aires: Cara o Ceca, 2011.

ARCEO, E. El impacto de la globalización en la periferia y las nuevas y viejas formas de la dependencia en América Latina. Cuadernos del Cendes, 22(60), 25-61, 2005.

ARRIGHI, G.; SILVER, B.; BREWER, B. Industrial Convergence, Globalization, and the Persistence of North-South Divide. Studies in Comparative International Development, 38(1), 3-31, 2003.

ARRIGHI, G. El largo siglo XX. Madrid: Akal. 1999.

AZPIAZU, D.; SCHORR, M. Hecho en Argentina. Industria y economía, 1976-2007. Buenos Aires: Siglo XXI Editores, 2010.

BALDWIN, R. Trade and Industrialization after globalization's 2nd unbundling: how building and joining a supply chain are different and why it matters. NBER Working paper, 17.716, 2011.

BASUALDO, E. Concentración y centralización del capital en la Argentina durante la década de los noventa. Buenos Aires: Flacso; Universidad Nacional de Quilmes, 2000. 
BIERSTEKER, T. Reducing the Role of the State in the Economy: A Conceptual Exploration of IMF and World Bank Prescriptions. International Studies Quarterly, 34(4), p. 477-492, 1990.

BRENNER, N.; PECK, J.; THEODORE, N. ¿Y después de la neoliberalización? Estrategias metodológicas para la investigación de las transformaciones regulatorias contemporáneas. Urban, 1, p. 21-40, 2011.

BRESSER-PEREIRA, L. C. Estado y mercado en el nuevo desarrollismo. Nueva Sociedad, 210, p. 110-125, 2007.

BRESSER-PEREIRA, L. C. El nuevo desarrollismo y la ortodoxia convencional. Economia-Unam, 4(10), p. 7-29, 2006.

CANITROT, A. La experiencia populista de redistribución de ingresos. Desarrollo Económico, 15(59), p. 331-351, 1975.

CASTELLS, M. El impacto de las nuevas tecnologías en la economía internacional. Implicaciones para la economía española. España: Ministerio de Economía y Hacienda, 1990.

CAVAROZZI, M. Más allá de las transiciones a la democracia en América Latina. Revista de Estudios Políticos, 74, p. 85-111, 1991.

CEPAL. Cambio estructural para la igualdad. Una visión integrada del desarrollo. San Salvador: Cepal, 2012.

CEPAL. Una década de desarrollo social en América Latina, 1990-1999. Santiago de Chile: CEPAL, 2004. CORDONE, H. Reseña histórica sobre la planificación económica en Argentina. CEIL-PEIETTE, Documento n. 3, 2004.

COX, R. Gramsci, hegemony and international relations: An essay in method. In: GILL, S. (ed.). Gramsci, Historical materialism and international relations. New York: Cambridge University Press, 1993.

CRESPI, G.; FERNÁNDEZ ARIAS, E.; STEIN, E. (eds.). ¿Cómo repensar el desarrollo productivo?: políticas e instituciones sólidas para la transformación económica. BID: Departamento de Investigación y Economista Jefe, 2014.

CROTTY, J. Trading State-Led Prosperity for Market-Led Stagnation: From the Golden Age to Global Neoliberalism. In: DYMSKI, G.; ISENBERG, D. (ed.). Housing Finance Futures: Housing Policies, Gender Inequality, and Financial Globalization on the Pacific Rim. M.E. Sharpe, Inc., 2000.

DAMIL, M.; FRENKEL, R. Las políticas macroeconómicas en la evolución reciente de la economía argentina, Nuevos Documentos Cedes, 65, 2009.

DICKEN, P. Global Shift: Transforming the World Economy. New York: Guilford Press, 1998.

EPSTEIN, G. Introduction: Financialization and the World Economy. In: EPSTEIN, G. (ed.). Financialization and the world economy. Great Britain: Edward Elgar Publishing, 2005.

EVANS, P. Developmental as Institutional Change: The Pitfalls of Monocropping and the Potentials of Deliberation. Studies in Comparative International Development, 38, 4, p. 30-52, 2004.

FERNÁNDEZ, V. R.; GARCÍA PUENTE, M. J. Revisando el Estado: perspectivas y lineamientos para el desarrollo de Latinoamérica. Perfiles, 40, p. 35-61, 2012.

FERNÁNDEZ, V. R.; CARDOZO, L. Nueva estatidad bajo la re-emergencia regional. La reelaboración del proyecto neoliberal y sus alternativas en la periferia. Estudios urbanos e regionais, 14(2), p. 11-33, 2012.

FERNÁNDEZ, V. R.; VIGIL, J. I.; GÜEMES, C. Quo vadis Banco Mundial? El Estado y el desarrollo en la agenda y en el discurso del organismo desde la mirada latinoamericana, Desenvolvimento em Questão, ljuí: Ed. Unijuí, 4(8), 35-73, 2006.

FERNÁNDEZ, V. R.; TEALDO, J.; VILLALBA, M. Industria, Estado y territorio en la Argentina de los '90. Santa Fe: Universidad Nacional del Litoral, 2005.

GAITÁN, F. Auge, ocaso y resurgimiento de los estudios sobre desarrollo en América Latina. CEPAL, Colección Documentos de proyectos. Santiago de Chile: Naciones Unidas, 2014.

GAITÁN, F. El rescate del Estado. Los desafíos del desarrollo. Buenos Aires: Capital Intelectual, 2013.

GEREFFI, G.; KORZENIEWICZ, M. Commodity Chains and Global Capitalism. United States: Greenwood Publishing Group, 1994.

GORDON, D.; WEISSKOPF, T.; BOWLES, S. Power, Accumulation, and Crisis: The Rise an Demise of the Postwar Social Structure of Accumulation. In: CHERRY, R. (ed.). The Imperiled Economy, book I, Macroeconomics from a left perspective. New York: The Union for Radical Political Economics, 1987.

GRUGEL, J.; RIGGIROZZI, P. Post-neoliberalism in Latin America: Rebulding and Reclaming the State after Crisis. Developmente and Change, 43(1), p. 1-21, 2012.

HARVEY, D. Neoliberalism as Creative Destruction. The ANNALS of the American Academy of Political and Social Science, 610(1), p. 22-44, 2007. 
HARVEY, D. La condición de la posmodernidad. Investigación sobre los orígenes del cambio cultural. Buenos Aires: Amorrortu Editores, 1998.

INAP. Organización del Estado y de la Administración Pública Nacional de la República Argentina. Argentina, 2000.

INAP. Reseña del proceso de reforma del Estado en la Argentina, 1989-1996. Argentina, 1997.

JESSOP, B. The Developmental State in an Era of Finance-Dominated Accumulation. In: CENTER, S. A. (ed.). Geo-political Economies of East Asia. Seoul, 2013a.

JESSOP, B. Finance-Dominated Accumulation and the Limits to Institutional and Spatio-Temporal Fixes in Capitalism. In: JANSEN, S.; SCHÖTER, E.; STEHR, N. (ed.). Fragile Stabilität - stabile Fragilität. Wiesbaden: Springer Fachmedien, 2013b. p. 303-328.

JESSOP, B. Narrating the future of the national economy and the national state? Remarks on remapping regulation and reinventing governance. In: STEINMETZ, G. (ed.) State/culture: State formation after the cultural turn. New York: Cornell University Press, 1999.

JESSOP, B. Putting states in their place: once more on capitalist states and capitalist societies. In: JESSOP, B. (ed.) State Theory: putting capitalist state in their place. Pensilvânia, EUA: Penn State University Press, 1990.

KANTIS, H. Cluster y nuevos polos emprendedores intensivos en conocimiento en Argentina. Buenos Aires: Universidad Nacional General Sarmiento, 2005.

KATZ, C. Las crisis recientes de la periferia. Realidad Económica, 183, p. 18-43, 2001.

KOTZ, D. Neoliberalism and Financialization. Department of Economics University of Massachusetts Amherst. Massachusetts: University of Massachusetts, 2008.

LACABANA, M.; MAINGON, T. La focalización: políticas sociales "estructuralmente ajustadas". Cuadernos del Cedes, 34, p. 193-218, 1997.

LAZONICK, W. The Financialization of the US Corporation: What Has Been Lost, and How It Can Be Regained. Seattle University Law Review, 36(2), p. 857-909, 2013.

LIBREROS, D.; CARRERO, D. Financiarización, crecimiento inestable y vulnerabilidad económica en América Latina y Colombia 1990-2013. In: America Latina en medio de la crisis mundial. Trayectorias nacionales y tendencias regionales. Bogotá: Clacso, 2014. p. 127-150.

LLACH, J. Otro siglo, otra Argentina. Una estrategia para el desarrollo económico y social nacida de la convertibilidad y su historia. Buenos Aires: Ariel Sociedad Económica, 1997.

LÓPEZ, B. Políticas sociales comparadas. Cuadernos Cepas, 13, 2003.

MAHUTGA, M. The Persistence of Structural Inequality? A Network Analysis of International Trade, 19652000. Social Forces, 84(4), p. 1.863-1.889, 2006.

MANZANAL, M. Globalización y ajuste en la realidad regional argentina: reestructuración o difusión de la pobreza? Realidad Económica, 134, p. 64-82, 1995.

MELO, A.; RODRígueZ CLARE, A. Políticas e instituciones de desarrollo productivo. In: LORA, E. (ed.). EI estado de las reformas del Estado en América Latina. Banco Interamericano de Desarrollo, 2006.

MILBERG, W. Shifting Sources and Uses of Profits: Sustaining U.S. Financialization with Global Value Chains. Economy and Society, 37(3), p. 420-451, 2008.

MINISTERIO DE INDUSTRIA. Plan estratégico industrial 2020. Buenos Aires, 2011.

OCAMPO, J. A.; ROS, J. Shifting Paradigms in Latin America's Economic Development. In: OCAMPO, J. A.; ROS, J. (ed.). The Oxford Handbook of Latin America Economics. New York: Oxford University Press, 2011.

PALMA, J. G. The revenge of the market on the rentiers. Why neo-liberal reports of the end of history turned out to be premature. Cambridge Journal of Economics, 33(4), p. 829-869, 2009.

PAUTASSI, L. Seguridad y protección social. Lecciones de la experiencia Argentina. In: MAURINO, G.; BERCOVICH, L. (coord.). Los Derechos Sociales en el Área Metropolitana de Buenos Aires: Una aproximación desde la Teoría, las instituciones y la acción en el Área Metropolitana de Buenos Aires. Buenos Aires: Eudeba, 2013.

PECK, J. Neoliberalizing states: thin policies/hard outcomes. Progress in Human Geography 25(3), p. 445455, 2001.

PERES, W. El lento retorno de las políticas industriales en América Latina y el Caribe. Cepal, 88, p. 71-88, 2006.

PORTES, A.; HOFFMAN, K. Las estructuras de clase en América Latina: composición y cambios durante la época neoliberal. Santiago de Chile: Cepal, 2003.

REPETTO, F.; POTENZA DAL MASETTO, F. Protección Social en Argentina. Santiago de Chile: Cepal, 2011. 
RAMOS, J. Una estrategia de desarrollo a partir de los complejos productivos (cluster) en torno a los recursos naturales. ¿Una estrategia prometedora? Santiago de Chile: Cepal, 1998.

ROFMAN, A. Desarrollo regional y exclusión social. Transformaciones y crisis en la Argentina contemporánea. Buenos Aires: Amorrortu Editores, 2000.

ROFMAN, A. Economías regionales. Modernización productiva y exclusión social en las economías regionales. Realidad Económica, 162, p. 107-136, 1999.

RORMAN, A. La política económica y el desarrollo regional. Bogotá: Ediciones Universidad y Pueblo, 1981. SAAD-FILHO, A. Growth, Poverty and Inequality: From Washington Consensus to Inclusive Growth. DESA Working Paper, 100, 2010.

SADER, E. Postneoliberalism in Latin America. Development Dialogue, 51, p. 170-179, 2009.

SADER, E. América Latina ¿el eslabón más débil? New Left Reviwe, 52, p. 5-28, 2008a.

SADER, E. Refundar el Estado. Posneoliberalismo en América Latina. Buenos Aires: CTA-Clacso, 2008b.

SOLDANO, D.; ANDRENACCI, L. Aproximación a las teorías de la política social a partir del caso argentino. In: ANDRENACCI, L. (ed.). Problemas de política social argentina. Buenos Aires: Prometeo, 2006.

STOCKHAMMER, E. The finance-dominated accumulation regime, income distribution and the present crisis. Vienna University of Economics \& BA. Department of Economics Working Papers Series, 127, 2009.

VARESI, G. Acumulación y hegemonía en Argentina durante el kirchnerismo. Problemas del desarrollo, 187(47), p. 63-87, 2016.

VILAS, C. Descentralización de las Políticas Públicas: Argentina en la Década de 1990. Dirección de Estudios e Información-INAP. 2003.

WORLD BANK. Strengthening political economy understanding for growth analysis. London: DFID-World Bank, 2008.

WORLD BANK. Economic Growth in the 1990s: Learning for a decade of reform. Washington, D.C.: World Bank, 2005.

YATES, J.; BAKKER, K. Debating the post-neoliberal turn in Latin America. Progress in Human Geography, volume: 38 issue: 1, p. 1-29, 2013. 


\section{Anexo I}

\begin{tabular}{|c|c|c|}
\hline $\begin{array}{l}\text { Decreto } 355 \text { PODER } \\
\text { EJECUTIVO NACIONAL (P.E.N.) } \\
20 / 07 / 1989\end{array}$ & $\begin{array}{l}\text { Decreto } 479 \text { PODER } \\
\text { EJECUTIVO NACIONAL } \\
\text { (P.E.N.) } 19 / 03 / 1990\end{array}$ & $\begin{array}{l}\text { Esquema ministerial vigente a finales } \\
\text { del mandato presidencial de Cristina } \\
\text { Fernández de Kirchner }\end{array}$ \\
\hline $\begin{array}{l}\text { MINISTERIO DEL INTERIOR } \\
\text { Subsecretaría del Interior } \\
\text { Subsecretaría de Asuntos } \\
\text { Institucionales } \\
\text { Subsecretaría de Asuntos } \\
\text { Técnico-Económicos } \\
\text { Secretaría de Acción } \\
\text { Cooperativa } \\
\text { Subsecretaría de Acción } \\
\text { Cooperativa }\end{array}$ & $\begin{array}{l}\text { MINISTERIO DEL } \\
\text { INTERIOR } \\
\text { Subsecretaría del } \\
\text { Interior. } \\
\text { Subsecretaría de Acción } \\
\text { Política. } \\
\text { Subsecretaría de } \\
\text { Asuntos Institucionales. } \\
\text { Subsecretaría de } \\
\text { Coordinación. }\end{array}$ & $\begin{array}{l}\text { MINISTERIO DEL INTERIOR Y TRANSPORTE } \\
\text { Subsecretaría de Coordinación } \\
\text { Secretaría de Interior } \\
\text { Subsecretaría de Interior } \\
\text { Secretaría de Asuntos Políticos } \\
\text { Subsecretaría de Asuntos Políticos y } \\
\text { Electorales } \\
\text { Secretaría de Provincias } \\
\text { Subsecretaría de Desarrollo y Fomento } \\
\text { Provincial } \\
\text { Secretaría de Asuntos Municipales } \\
\text { Subsecretaría de Gestión Municipal } \\
\text { Secretaría de Transporte } \\
\text { Subsecretaría de Administración del } \\
\text { Transporte } \\
\text { Subsecretaría de Transporte Aerocomercial } \\
\text { Subsecretaría de Transporte Ferroviario } \\
\text { Subsecretaría de Transporte Automotor } \\
\text { Subsecretaría de Puertos y Vías Navegables } \\
\text { Subsecretaría de Regulación Normativa del } \\
\text { Transporte }\end{array}$ \\
\hline $\begin{array}{l}\text { MINISTERIO DE RELACIONES } \\
\text { EXTERIORES Y CULTO } \\
\text { Subsecretaría de Relaciones } \\
\text { Internacionales Económicas } \\
\text { Subsecretaría Técnica y de } \\
\text { Coordinación } \\
\text { Secretaría de Relaciones } \\
\text { Internacionales y Culto } \\
\text { Subsecretaría de Política } \\
\text { Exterior } \\
\text { Subsecretaría de Asuntos } \\
\text { Latinoamericanos } \\
\text { Subsecretaría de Culto } \\
\text { Subsecretaría de Cooperación } \\
\text { Internacional } \\
\text { Secretaría de Relaciones } \\
\text { Exteriores para Asuntos } \\
\text { Especiales } \\
\text { Subsecretaría de Asuntos } \\
\text { Australes y Limítrofes } \\
\text { Subsecretaría de Paz y } \\
\text { Seguridad Internacionales }\end{array}$ & $\begin{array}{l}\text { MINISTERIO DE } \\
\text { RELACIONES } \\
\text { EXTERIORES Y CULTO. } \\
\text { Subsecretaría de } \\
\text { Relaciones Exteriores. } \\
\text { Subsecretaría de Culto. } \\
\text { Subsecretaría } \\
\text { de Asuntos } \\
\text { Latinoamericanos. } \\
\text { Subsecretaría de } \\
\text { Asuntos Especiales. }\end{array}$ & $\begin{array}{l}\text { MINISTERIO DE RELACIONES EXTERIORES } \\
\text { Y CULTO } \\
\text { Secretaría de Relaciones Exteriores } \\
\text { Subsecretaría de Relaciones Institucionales } \\
\text { Subsecretaría de Política Latinoamericana } \\
\text { Subsecretaría de Política Exterior } \\
\text { Subsecretaría de Coordinación y } \\
\text { Cooperación Internacional } \\
\text { Subsecretaría Legal, Técnica y } \\
\text { Administrativa } \\
\text { Secretaría de Culto } \\
\text { Subsecretaría de Culto } \\
\text { Secretaría de Relaciones Económicas } \\
\text { Internacionales } \\
\text { Subsecretaría de Integración Económica } \\
\text { Latinoamericana y Mercosur } \\
\text { Subsecretaría de Desarrollo de Inversiones } \\
\text { y Promoción Comercial } \\
\text { Subsecretaría de Negociaciones } \\
\text { Económicas Internacionales } \\
\text { Secretaría de Asuntos Relativos a las Islas } \\
\text { Malvinas, Georgias del Sur, Sandwich del } \\
\text { Sur y los espacios marítimos circundantes } \\
\text { en el Atlántico Sur } \\
\text { Subsecretaría de Asuntos Relativos a } \\
\text { las Islas Malvinas, Georgias del Sur, } \\
\text { Sandwich del Sur y los espacios marítimos } \\
\text { circundantes en el Atlántico Sur }\end{array}$ \\
\hline
\end{tabular}




\begin{tabular}{|c|c|c|}
\hline $\begin{array}{l}\text { MINISTERIO DE DEFENSA } \\
\text { Subsecretaría de Defensa } \\
\text { Subsecretaría de Producción } \\
\text { para la Defensa } \\
\text { Subsecretaría de } \\
\text { Programación y Control } \\
\text { Presupuestario } \\
\text { Subsecretaría de Asuntos } \\
\text { Castrenses }\end{array}$ & $\begin{array}{l}\text { MINISTERIO DE } \\
\text { DEFENSA } \\
\text { Subsecretaría de } \\
\text { Defensa. } \\
\text { Subsecretaría de } \\
\text { Producción para la } \\
\text { Defensa. } \\
\text { Subsecretaría de } \\
\text { Planeamiento Técnico. }\end{array}$ & $\begin{array}{l}\text { MINISTERIO DE DEFENSA } \\
\text { Subsecretaría de Coordinación } \\
\text { Administrativa } \\
\text { Secretaría de Estrategia y Asuntos militares } \\
\text { Subsecretaría de Formación } \\
\text { Subsecretaría de Planeamiento Estratégico } \\
\text { y Política Militar } \\
\text { Subsecretaría de Asuntos Internacionales } \\
\text { de la Defensa } \\
\text { Secretaría de Ciencia, Tecnología y } \\
\text { Producción para la defensa } \\
\text { Subsecretaría de Gestión de Medios y de } \\
\text { Planificación Presupuestaria y Operativa } \\
\text { para la Defensa } \\
\text { Subsecretaría de Investigación, Desarrollo } \\
\text { y Producción para la Defensa. } \\
\text { Secretaría de Coordinación Militar de } \\
\text { Asistencia en Emergencias. } \\
\text { Subsecretaría de Coordinación Ejecutiva de } \\
\text { Emergencias } \\
\text { Subsecretaría de Planeamiento para la } \\
\text { Asistencia en Emergencias. }\end{array}$ \\
\hline & & $\begin{array}{l}\text { MINISTERIO DE SEGURIDAD } \\
\text { Secretaría de Coordinación, Planeamiento } \\
\text { y Formación } \\
\text { Subsecretaría de Gestión Administrativa } \\
\text { Subsecretaría de Asuntos Jurídicos } \\
\text { Subsecretaría de Planeamiento y } \\
\text { Formación } \\
\text { Secretaría de Seguridad } \\
\text { Subsecretaría de Políticas de Seguridad e } \\
\text { Intervención Territorial } \\
\text { Subsecretaría de Logística } \\
\text { Subsecretaría de Participación Ciudadana } \\
\text { Subsecretaría de Investigación del Delito } \\
\text { Organizado y Complejo } \\
\text { Subsecretaria de Protección Civil y } \\
\text { Abordaje Integral de Emergencias y } \\
\text { Catástrofes } \\
\text { Subsecretaría de Lucha contra el } \\
\text { Narcotráfico } \\
\text { Secretaría de Cooperación con los } \\
\text { Poderes Judiciales, Ministerios Públicos y } \\
\text { Legislaturas } \\
\text { Subsecretaría de Articulación con los } \\
\text { Poderes Judiciales y los Ministerios } \\
\text { Públicos } \\
\text { Subsecretaría de Articulación Legislativa }\end{array}$ \\
\hline
\end{tabular}




\begin{tabular}{|c|c|c|}
\hline 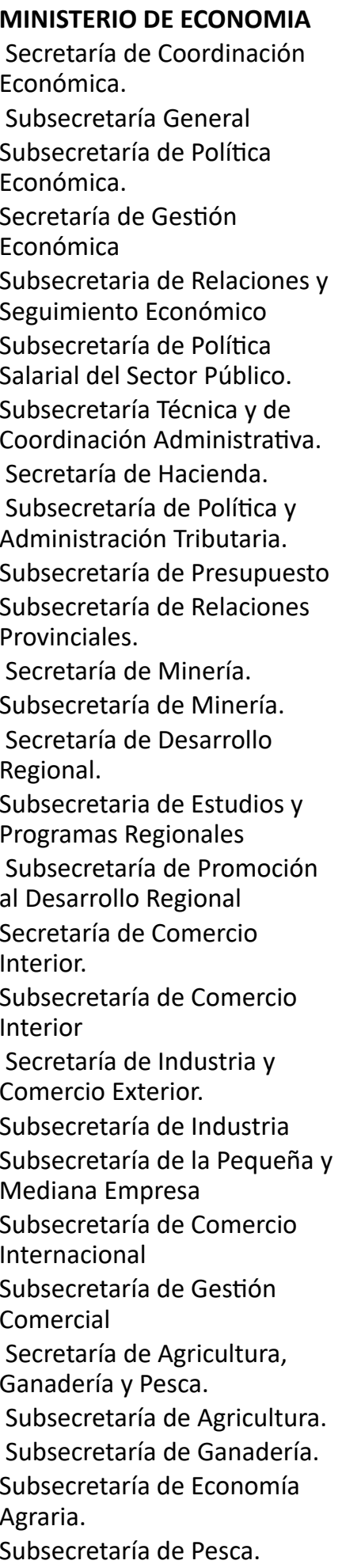 & $\begin{array}{l}\text { MINISTERIO DE } \\
\text { ECONOMIA } \\
\text { Subsecretaría de } \\
\text { Economía. } \\
\text { Subsecretaría de } \\
\text { Hacienda. } \\
\text { Subsecretaría de } \\
\text { Finanzas Públicas. } \\
\text { Subsecretaría de } \\
\text { Empresas Públicas. } \\
\text { Subsecretaría de } \\
\text { Industria y Comercio. } \\
\text { Subsecretaría } \\
\text { de Coordinación } \\
\text { Administrativa y Técnica. } \\
\text { Subsecretaría de } \\
\text { Agricultura, Ganadería } \\
\text { y Pesca. }\end{array}$ & $\begin{array}{l}\text { MINISTERIO DE ECONOMIA Y FINANZAS } \\
\text { PUBLICAS } \\
\text { Secretaría de Política Económica y } \\
\text { Planificación del Desarrollo } \\
\text { Subsecretaría de Programación } \\
\text { Macroeconómica } \\
\text { Subsecretaría de Coordinación Económica } \\
\text { y Mejora de la Competitividad } \\
\text { Subsecretaría de Planificación Económica } \\
\text { Secretaría de Comercio } \\
\text { Subsecretaría de Comercio Interior } \\
\text { Subsecretaría de Comercio Exterior } \\
\text { Secretaría de Finanzas } \\
\text { Subsecretaría de Servicios Financieros } \\
\text { Subsecretaría de Financiamiento } \\
\text { Secretaría de Hacienda } \\
\text { Subsecretaría de Presupuesto } \\
\text { Subsecretaría de Relaciones con Provincias } \\
\text { Subsecretaría de Ingresos Públicos } \\
\text { Secretaría Legal y Administrativa } \\
\text { Subsecretaría Legal } \\
\text { Subsecretaría de Administración y } \\
\text { Normalización Patrimonial } \\
\text { Subsecretaría de Relaciones } \\
\text { Internacionales }\end{array}$ \\
\hline
\end{tabular}




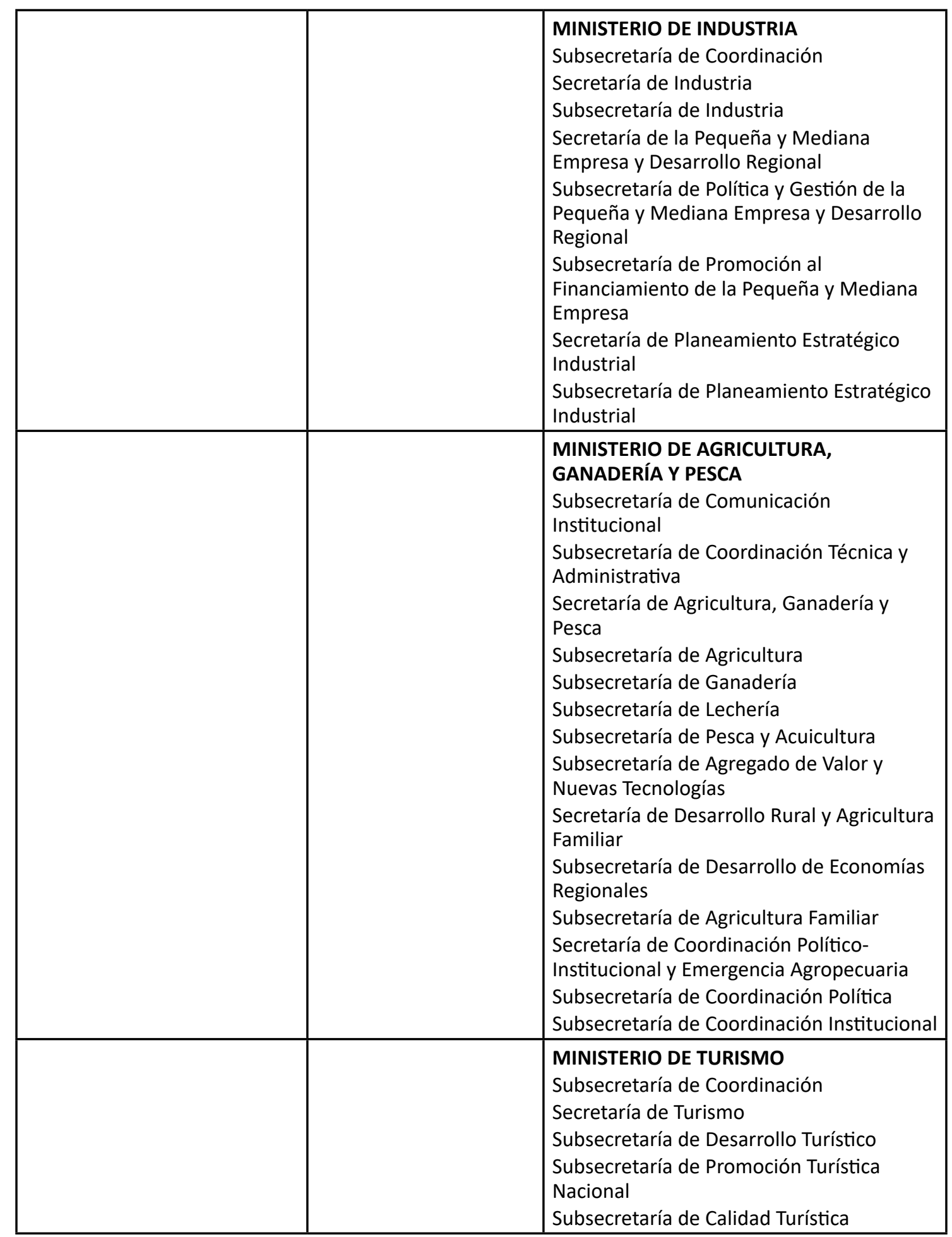




\section{MINISTERIO DE OBRAS Y SERVICIOS PÚBLICOS}

Subsecretaría de Obras y

Servicios Públicos

Secretaría de Comunicaciones

Subsecretaría de

Telecomunicaciones

Subsecretaría de

Radiodifusión

Secretaría de Recursos

Hídricos

Subsecretaría de Recursos

Hídricos

Secretaría de Transporte

Subsecretaría de Transporte

Terrestre

Subsecretaría de Transporte

Fluvial y Marítimo

Subsecretaría de Planificación

del Transporte

Secretaría de Energía

Subsecretaría de Energía

Eléctrica

Subsecretaría de Gestión

Empresarial

Subsecretaría de Combustibles Subsecretaría de Planificación Energética

MINISTERIO DE EDUCACIÓN Y JUSTICIA

Secretaría de Coordinación

Educacional, Científica y

Cultural

Subsecretaría de Coordinación

Educacional, Científica y

Cultural

Secretaría de Educación

Subsecretaría de Conducción

Educativa

Subsecretaría de la Actividad

Profesional Docente

Secretaría de Justicia

Subsecretaría de Justicia

Subsecretaría de Asuntos

Legislativos

Secretaría de Cultura

Subsecretaría de Cultura
MINISTERIO DE OBRAS Y SERVICIOS PUBLICOS

Subsecretaría de Energía.

Subsecretaría de Obras

Públicas.

Subsecretaría de

Transportes.

Subsecretaría de

Servicios Públicos.
MINISTERIO DE PLANIFICACIÓN FEDERAL, INVERSIÓN PÚBLICA Y SERVICIOS

Subsecretaría de Coordinación y Control de Gestión

Subsecretaría Legal

Subsecretaría de Planificación Territorial de la Inversión Pública

Secretaría de Obras Públicas

Subsecretaría de Obas Públicas

Subsecretaría de Coordinación de la Obra Pública Federal

Subsecretaría de Recursos Hídricos

Subsecretaría de Desarrollo Urbano y

Vivienda

Secretaría de Minería

Secretaría de Energía

Subsecretaría de Energía Eléctrica

Subsecretaría de Combustibles

Secretaría de Comunicaciones

\section{MINISTERIO DE} EDUCACION Y JUSTICIA

Subsecretaría de Coordinación Educacional, Científica y Cultural.

Subsecretaría de Educación.

Subsecretaría de Cultura.

Subsecretaría de Justicia.

\section{MINISTERIO DE JUSTICIA Y DERECHOS}

\section{HUMANOS}

Subsecretaría de Coordinación

Subsecretaría de Planificación Estratégica

Secretaría de Justicia

Subsecretaría de Relaciones con el Poder Judicial y Asuntos Penitenciarios

Subsecretaría de Política Criminal

Subsecretaría de Acceso a la Justicia

Secretaría de Asuntos Registrales

Subsecretaría de Coordinación y Control de Gestión Registral

Secretaría de Derechos Humanos

Subsecretaría de Protección de Derechos

Humanos

Subsecretaría de Promoción de Derechos

Humanos 


\begin{tabular}{|c|c|c|}
\hline & & $\begin{array}{l}\text { MINISTERIO DE EDUCACIÓN } \\
\text { Subsecretaría de Coordinación } \\
\text { Administrativa } \\
\text { Secretaría de Educación } \\
\text { Subsecretaría de Equidad y Calidad } \\
\text { Educativa } \\
\text { Subsecretaría de Planeamiento Educativo } \\
\text { Subsecretaría de Enlaces Institucionales } \\
\text { Secretaría de Políticas Universitarias } \\
\text { Subsecretaría de Gestión y Coordinación } \\
\text { de Políticas Universitarias }\end{array}$ \\
\hline & & $\begin{array}{l}\text { MINISTERIO DE CIENCIA, TECNOLOGÍA E } \\
\text { INNOVACIÓN PRODUCTIVA } \\
\text { Subsecretaría de Coordinación } \\
\text { Administrativa } \\
\text { Secretaría de Planeamiento y Políticas en } \\
\text { CTeIP } \\
\text { Subsecretaria de Estudios y Prospectiva } \\
\text { Subsecretaría de Políticas CTeIP } \\
\text { Secretaría de Articulación Científico- } \\
\text { Tecnológica } \\
\text { Subsecretaría de Coordinación Institucional } \\
\text { Subsecretaría de Evaluación Institucional }\end{array}$ \\
\hline & & $\begin{array}{l}\text { MINISTERIO DE CULTURA } \\
\text { Secretaría de Coordinación y Control de } \\
\text { Gestión } \\
\text { Secretaría de Gestión Cultural } \\
\text { Secretaría de Políticas Socio-culturales } \\
\text { Subsecretaría de Promoción de Derechos } \\
\text { Culturales y Participación Popular } \\
\text { Secretaría de Coordinación Estratégica } \\
\text { para el Pensamiento Nacional }\end{array}$ \\
\hline $\begin{array}{l}\text { MINISTERIO DE TRABAJO Y } \\
\text { SEGURIDAD SOCIAL } \\
\text { Subsecretaría de Trabajo y } \\
\text { Seguridad Social } \\
\text { Secretaría de Trabajo } \\
\text { Subsecretaría de Trabajo } \\
\text { Subsecretaría Técnica y de } \\
\text { Coordinación Administrativa } \\
\text { Secretaría de Seguridad Social } \\
\text { Subsecretaría de Seguridad } \\
\text { Social }\end{array}$ & $\begin{array}{l}\text { MINISTERIO DE } \\
\text { TRABAJO Y SEGURIDAD } \\
\text { SOCIAL } \\
\text { Subsecretaría de } \\
\text { Trabajo. } \\
\text { Subsecretaría de } \\
\text { Seguridad Social. }\end{array}$ & $\begin{array}{l}\text { MINISTERIO DE TRABAJO, EMPLEO Y } \\
\text { SEGURIDAD SOCIAL } \\
\text { Subsecretaría de Programación Técnica y } \\
\text { Estudios Laborales } \\
\text { Subsecretaría de Coordinación } \\
\text { Secretaría de Trabajo } \\
\text { Subsecretaría de Relaciones Laborales } \\
\text { Subsecretaría de Fiscalización del Trabajo y } \\
\text { de la Seguridad Social } \\
\text { Secretaría de Empleo } \\
\text { Subsecretaría de Políticas de Empleo y } \\
\text { Formación Profesional } \\
\text { Subsecretaría de Promoción del Sector } \\
\text { Social de la Economía } \\
\text { Secretaría de Seguridad Social } \\
\text { Subsecretaría de Políticas de la Seguridad } \\
\text { Social } \\
\text { Subsecretaría de Coordinación de los } \\
\text { Regímenes de la Seguridad Social }\end{array}$ \\
\hline
\end{tabular}




\begin{tabular}{|c|c|c|}
\hline $\begin{array}{l}\text { MINISTERIO DE SALUD Y } \\
\text { ACCIÓN SOCIAL } \\
\text { Subsecretaría de Salud y } \\
\text { Acción Social } \\
\text { Secretaría de Salud } \\
\text { Subsecretaría de Regulación } \\
\text { y Control } \\
\text { Subsecretaría de Recursos de } \\
\text { Salud } \\
\text { Subsecretaría de Programas } \\
\text { de Salud } \\
\text { Secretaría de Deporte } \\
\text { Subsecretaría de Deporte } \\
\text { Secretaría de Promoción } \\
\text { Social } \\
\text { Subsecretaría de Promoción } \\
\text { Social } \\
\text { Secretaría de Desarrollo } \\
\text { Humano y Familia } \\
\text { Subsecretaría de Desarrollo } \\
\text { Humano y Familia } \\
\text { Secretaría de Vivienda y } \\
\text { Ordenamiento Ambiental } \\
\text { Subsecretaría de Vivienda y } \\
\text { Ordenamiento Ambiental }\end{array}$ & $\begin{array}{l}\text { MINISTERIO DE SALUD } \\
\text { Y ACCION SOCIAL } \\
\text { Subsecretaría de Acción } \\
\text { Social. } \\
\text { Subsecretaría de Salud. } \\
\text { Subsecretaría de } \\
\text { Coordinación y } \\
\text { Administración de Salud } \\
\text { y Acción Social. } \\
\text { Subsecretaría } \\
\text { de Vivienda y } \\
\text { Ordenamiento } \\
\text { Ambiental. }\end{array}$ & $\begin{array}{l}\text { MINISTERIO DE DESARROLLO SOCIAL } \\
\text { Secretaría de Coordinación y Monitoreo } \\
\text { Institucional } \\
\text { Subsecretaría de Coordinación, Monitoreo } \\
\text { y Logística } \\
\text { Subsecretaría de Comercialización de la } \\
\text { Economía Social } \\
\text { Subsecretaría de Responsabilidad Social } \\
\text { Secretaría de Economía Social } \\
\text { Subsecretaría de Fortalecimiento } \\
\text { Institucional } \\
\text { Subsecretaría de Organización de Ingresos } \\
\text { Sociales } \\
\text { Subsecretaría de Políticas Alimentarias } \\
\text { Secretaría de Organización y Comunicación } \\
\text { Comunitaria } \\
\text { Subsecretaría de Juventud } \\
\text { Subsecretaría de Organización y } \\
\text { Capacitación Popular } \\
\text { Subsecretaría de Organización Comunitaria } \\
\text { Secretaría de Gestión y Articulación } \\
\text { Institucional } \\
\text { Subsecretaría de Abordaje Territorial } \\
\text { Secretaría Nacional de Niñez, Adolescencia } \\
\text { y Familia } \\
\text { Subsecretaría de Derechos para la Niñez, } \\
\text { Adolescencia y Familia } \\
\text { Subsecretaría de Desarrollo Institucional e } \\
\text { Integración Federal } \\
\text { Secretaría de Deporte } \\
\text { Subsecretaría de Planeamiento y Gestión } \\
\text { Productiva } \\
\text { Subsecretaría de Recursos Deportivos }\end{array}$ \\
\hline
\end{tabular}

